\title{
EVOLUTION OF THE MODULATED ELECTRON BEAM IN THE DENSE PLASMA BARRIER
}

\author{
I.O. Anisimov, M.J. Soloviova \\ Taras Shevchenko National University of Kiev, Radio Physics Faculty, Kiev, Ukraine
E-mail: ioa@univ.kiev.ua, mariia.soloviova@gmail.com
}

Dynamics of the modulated electron beam moving through the dense plasma barrier was studied via computer simulation using PIC method. Effects of the competition between the resonant mode of a beam-plasma system and space charge wave of the beam at the modulation frequency are discussed. Influence of plasma inhomogeneity and beam-plasma turbulence mode on the evolution of the beam was studied. For 2D simulation the influence of the beam transversal restriction is discussed.

PACS: 52.35.Qz, 52.65.Rr

\section{INTRODUCTION}

Problem of the evolution of modulated electron beams in plasma is interesting due to its possible applications such as dense plasma barrier transillumination for electromagnetic waves using electron beams [1,2], planning of the experiments on electron beams' injection into space and ionosphere plasma and interpretation of their results [3, 4], diagnostics of inhomogeneous plasma via transition radiation of electron beams [5] etc.

Evolution of the modulated electron beam in the supercritical plasma barrier was studied experimentally in $[1,2]$. It was shown that signal at the modulation frequency reached its maximum inside the barrier, and magnitude of this maximum was directly proportional to the initial beam modulation depth. These results were explained in [6] by the competition between non-resonant (signal) and resonant (noise) modes of the beam-plasma system. But calculations presented in [6] correspond to the initial problem, whereas results of experiments $[1,2]$ correspond to the boundary problem. So it was impossible to compare simulation results with experimental data.

This report presents simulations' results of dynamics of the modulated electron beam in the dense plasma barrier for various ranges of parameters, such as initial beam modulation depth, electron beam current density (which defines the mode of beam-plasma turbulence) etc. Also different barriers' profiles were studied (homogeneous and Gaussian shape). As for real beams of finite radius the radial component of electric field appears causing the electrons' and ions' radial motion, 1D model can't be used for complete beam-plasma interaction processes' description. 2D model was treated with thin modulated electron beam propagating in the plasma barrier. Simulations' results are compared with previous laboratory experiments.

\section{MODEL DESCRIPTION, SIMULATION METHOD AND PARAMETERS}

Warm isotropic collisionless plasma with initial homogeneous and Gaussian density profile was studied. Simulations were carried out via PIC method using program packages PDP1 $[7,8]$ and PDP2 $[9,10]$ for 1D and $2 \mathrm{D}$ models respectively. Region between two plane electrodes was simulated. Interelectrode space was filled with fully ionized hydrogen plasma. Initial plasma density profile was either homogeneous or obtained by the approximation of experimental axial plasma density profile $[1,2]$ by Gaussian function. Some of simulation parameters are: plasma density $-10^{10} \ldots 10^{11} \mathrm{~cm}^{-3}$, plasma electrons' and ions' thermal energy $-10 \mathrm{eV}$, simulation region length - $20 \mathrm{~cm}$, beam electrons velocity $2 \cdot 10^{9} \mathrm{~cm} / \mathrm{s}$, beam modulation frequency $2,6 \ldots 2.9 \mathrm{GHz}$, simulation time step $10^{-13} \ldots 10^{-12} \mathrm{~s}$, electron beam modulation depth $0.01 \ldots 0.4$. Electron beam was injected into plasma barrier from one electrode and moved to the other one. Electrodes absorbed both plasma and beam particles. Initially electron beam was density-modulated with modulation depth $m$. Modulation frequency was selected in such a way that there was interval inside the barrier (in the case of homogeneous density profile the interval was equivalent to the whole barrier) where electron plasma frequency $\omega_{p}(n)$ (corresponding to the plasma density $n$ ) exceeded the modulation frequency. In the case of Gaussian density profile two local plasma resonance regions at the modulation frequency existed inside the barrier. Simulations were carried out during the time interval of approximately 200 electron plasma periods or 5 ion plasma periods. During this time electron beam reached the opposite electrode and quasi-stationary regime was settled.

\section{SIMULATION RESULTS}

It is shown that competition between the resonant mode and the signal mode leads to the suppression of the non-resonant mode (Fig. 1, a), as it was proposed earlier on the basis of simulation results of initial problem with periodic boundary conditions [6]. In contrast to the previous simulations it is obtained that the resonance instability occurs in the broad frequency band (Fig. 1, b). This fact corresponds to the experimental results $[1,2]$. Frequency band expansion (for the resonant instability) was explained by the processes of 1-s decay of the Langmuir wave initially excited by the beam [11].

During the beam propagation in the plasma barrier the most part of the beam electrons is decelerated. Appearance of secondary bunches can be connected with front reversal in the phase space. Comparison of pictures for modulated and non-modulated beams (Fig. 2, a, b) shows that sufficiently large initial modulation depth suppresses resonant instability development [12]. 



Fig. 1. Space dependence of the signal amplitude at the modulation frequency (A) and resonant frequency (B) (a) and spatial evolution of spectra of the electron beam density for modulation depth $m=0.3$ (arrow marks the signal modulation frequency) (b)

Dynamics of the modulated electron beam in the inhomogeneous plasma barrier (Fig. 3) is determined by relations between the barrier length $\mathrm{L}$, characteristic length of the plasma inhomogeneity in barrier $\Delta x$, and beam-plasma instability development length $\mathrm{a} / \gamma$ [13]. Small increments' mode corresponds to the relation $\mathrm{a} / \gamma>\mathrm{L}>\Delta \mathrm{x}$, moderate increments' mode $-\mathrm{L}>\mathrm{a} / \gamma>\Delta \mathrm{x}$, large increments' mode $-\mathrm{L}>\Delta \mathrm{x}>\mathrm{a} / \gamma$.

Interaction of modes at the modulation frequency and resonant mode frequency differs strongly for various electron beam current densities: both resonant and nonresonant increments are very small in the weak turbulence mode, modulation instability was observed in the strong turbulence mode, and quasi-periodic transillumination of plasma for electron beam was observed for super strong turbulence mode. Experiments [4, 5] also demonstrated that plasma barriers' transillumination using beams with large current densities is impossible, and simulation results [14] confirmed and explained this conclusion.

In 2D geometry modes' competition is completed by trapping of the beam electrons by resonant mode and suppression of the signal mode at the modulation frequency [14] as it was observed in 1D simulation [6]
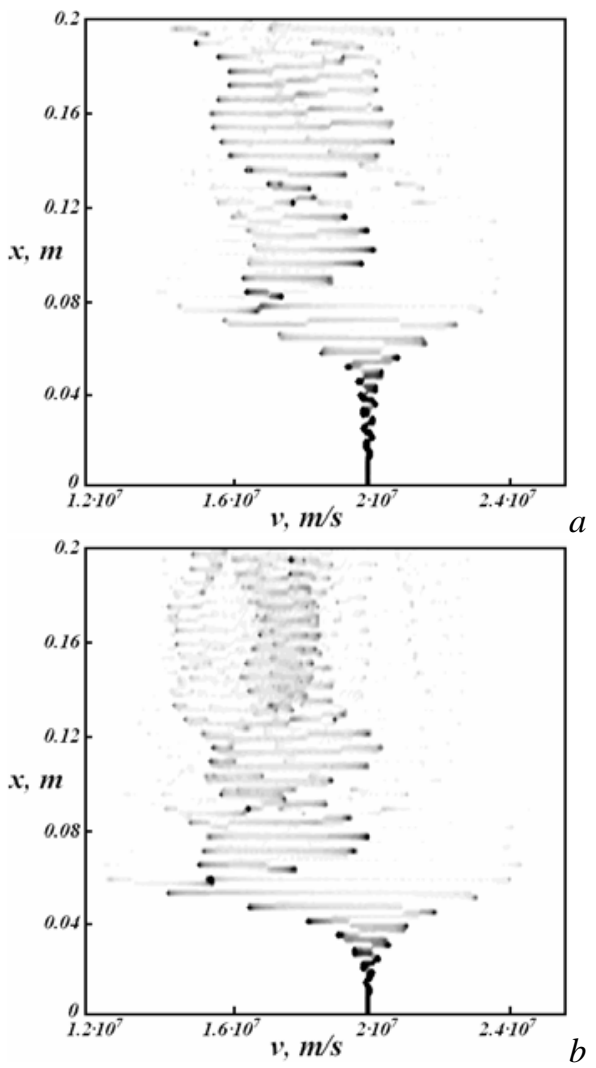

Fig. 2. Velocity distribution functions of beam electrons for modulated $(m=0.3)(a)$ and for non-modulated $(m=0)$

(b) electron beam at the time moment $t=4 \cdot 10^{-8} \mathrm{~S}$

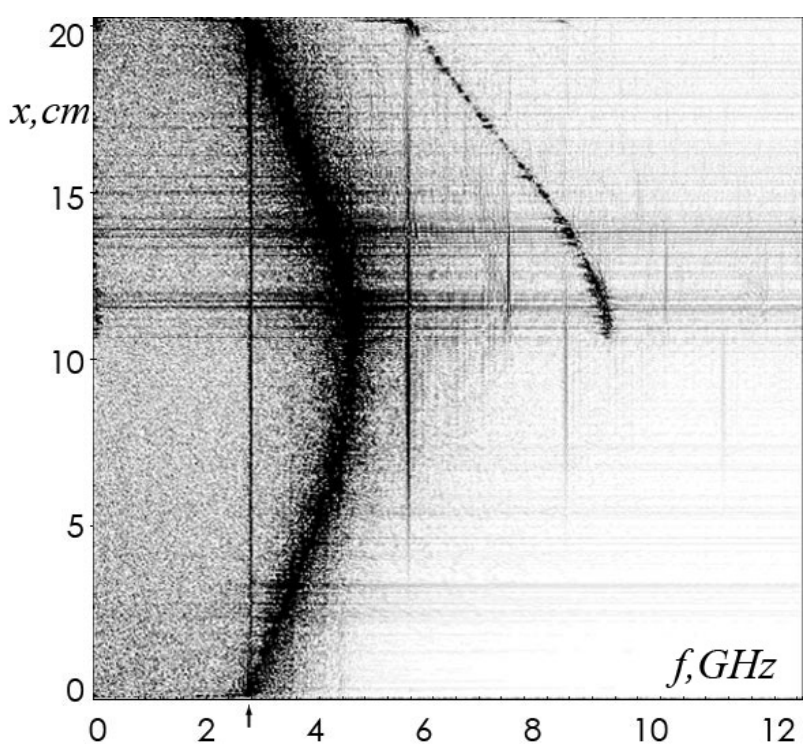

Fig. 3. Spatial evolution of spectra of the electric field strength (initial modulation depth $m=0.05$ )

Several essentially new effects were observed in comparison with simulations in 1D model: transversal and longitudinal focusing of the beam, beam's transverse filamentation, which is hypothetically caused by instability of the oblique space charge waves in the beam, and beam's transverse expansion (Fig.4). 


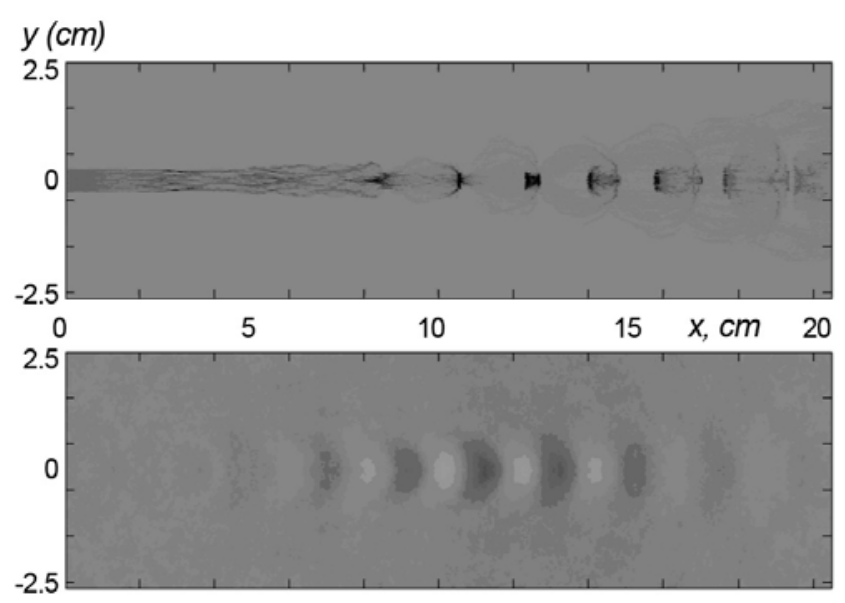

Fig.4. Spatial distribution of electron beam density (top) and electric potential (bottom) in time point $t=30 \mathrm{~ns}$

\section{REFERENCES}

1.I.O. Anisimov, S.M. Levitsky, O.V. Opanasenko, L.I. Romanyuk. Experimental observation of the plasma wave barrier transillumination by means of electron beam // JTPh. 1991, v. 61, N 3, p. 59-63 (In Russian).

2. I.O. Anisimov, I.Yu. Kotlyarov, S.M. Levitsky, O.V. Opanasenko, D.B. Palets, L.I. Romanyuk. Study of the plasma barriers transillumination for electromagnetic waves using electron beams. 2. Space charge waves evolution in the barrier // Ukr. Fiz. Zhurn. 1996, v. 41, N 3, p. 164-170 (In Ukrainian).

3. J. Lavergnat, R. Pellat. High-frequency spontaneous emission of an electron beam injected into the ionospheric plasma // Journ. of Geophys. Research. 1979 , v. 84, N A12, p. 7223-7238.

4. M. Starodubtsev, C. Krafft. Whistler emission through transition radiation by a modulated electron beam spiralling in a magnetoplasma // Journ. of Plasma Phys. 2000 , v. 63, N 3, p. 285-295.

5. I.O. Anisimov, K.I. Lyubich. Plasma-object diagnostics via resonant transition radiation from an electron bunch // Journ. of Plasma Phys. 2001, v. 66, N 3, p. 157-165.
6. I.O. Anisimov, S.V. Dovbakh, S.M. Levitsky, G.V. Lizunov, H.V. Podladchikova. Concurrence of modes in the signals' transport through the plasma wave barriers via electron beams // Kyiv Univ. Bulletin. Radiophys. \& Elec. 2000, N 2, p. 10-17 (In Ukrainian).

7. Ch. K. Birdsall, A.B. Langdon. Plasma Physics, via Computer Simulation. New York: "McGraw-Hill Book Company", 1985.

8. I.O. Anisimov, D.V. Sasyuk, T.V. Siversky. Modified package PDP1 for beam-plasma systems' simulation // Dynamical system modelling and stability investigation. Conference reports / Kyiv. 2003, p. 257.

9. I.O. Anisimov, T.Eu. Litoshenko. 2D electrostatic simulation of the modulated electron beam interaction with inhomogeneous plasma // Probl. of Atomic Sci. and Techn. Ser. "Plasma Physics"(12). 2006, N 6, p. 175.

10. I.O. Anisimov, T.Eu. Litoshenko. Dynamics of a modulated electron beam in homogeneous plasma: $2 \mathrm{D}$ simulation // Ukr. Fiz. Zhurn. 2008, N 4, p. 388-392.

11. I.O. Anisimov, M.J. Kiyanchuk. Evolution of the modulated electron beam in supercritical plasma: simulation of initial-boundary problem // Probl. of Atomic Sci. and Techn. Ser. "Plasma Electronics and New Acceleration Methods”(5). 2006, N 5, p. 24-27.

12. A. K. Berezin, Ya. B. Fainberg, I. A. Bezjazichniy. Experimental study of the possibility to control beam instability via modulation // Pis'ma v ZhETF. 1968, v. 7, N 5, p. 156-160.

13. I.O. Anisimov, M.J. Soloviova. Evolution of the modulated electron beam in the inhomogeneous plasma barrier for various beam current densities: 1D simulation// Kyiv Univ. Bulletin. Radiophys. \& Elec. 2010, N 13, p. 4-7.

14. I. O. Anisimov, M. J. Soloviova. 2D simulation of the transversely restricted modulated electron beam dynamics in the homogeneous plasma // Probl. of Atomic Sci. and Techn. Ser. "Plasma Electronics and New Acceleration Methods”(7). 2010, v. 7, N 4, p. 4346.

Article received 13.10 .10

\section{ЭВОЛЮЦИЯ МОДУЛИРОВАННОГО ЭЛЕКТРОННОГО ПУЧКА В БАРЬЕРЕ ПЛОТНОЙ ПЛАЗМЫ \\ И.А. Анисимов, М.И. Соловьёва}

С помощью компьютерного моделирования с применением метода крупных частиц изучена динамика модулированного электронного пучка в барьере плотной плазмы. Рассматриваются эффекты конкуренции резонансной моды плазменно-пучковой системы и волны пространственного заряда пучка на частоте модуляции. Изучено влияние на эволюцию электронного пучка таких параметров как неоднородности фоновой плазмы, режим плазменно-пучковой турбулентности и др. Для двухмерного моделирования рассматривается влияние поперечного ограничения пучка.

\section{ЕВОЛЮЦІЯ МОДУЛЬОВАНОГО ЕЛЕКТРОННОГО ПУЧКА В БАР'ЄРІ ГУСТОЇ ПЛАЗМИ I.O. Анісімов, М.Й. Соловйова}

За допомогою комп'ютерного моделювання методом крупних частинок вивчено динаміку модульованого електронного пучка, що рухається в бар'єрі густої плазми. Розглядаються ефекти конкуренції резонансної моди плазмово-пучкової системи і хвилі просторового заряду пучка на частоті модуляції. Досліджується вплив на еволюцію електронного пучка таких параметрів як неоднорідності фонової плазми, режим плазмово-пучкової турбулентності та ін. Для двохвимірного моделювання розглядається вплив поперечного обмеження пучка. 